\section{Tumor seeding after endoscopic ultrasound-guided fine-needle aspiration of cancer in the body of the}

\section{pancreas}
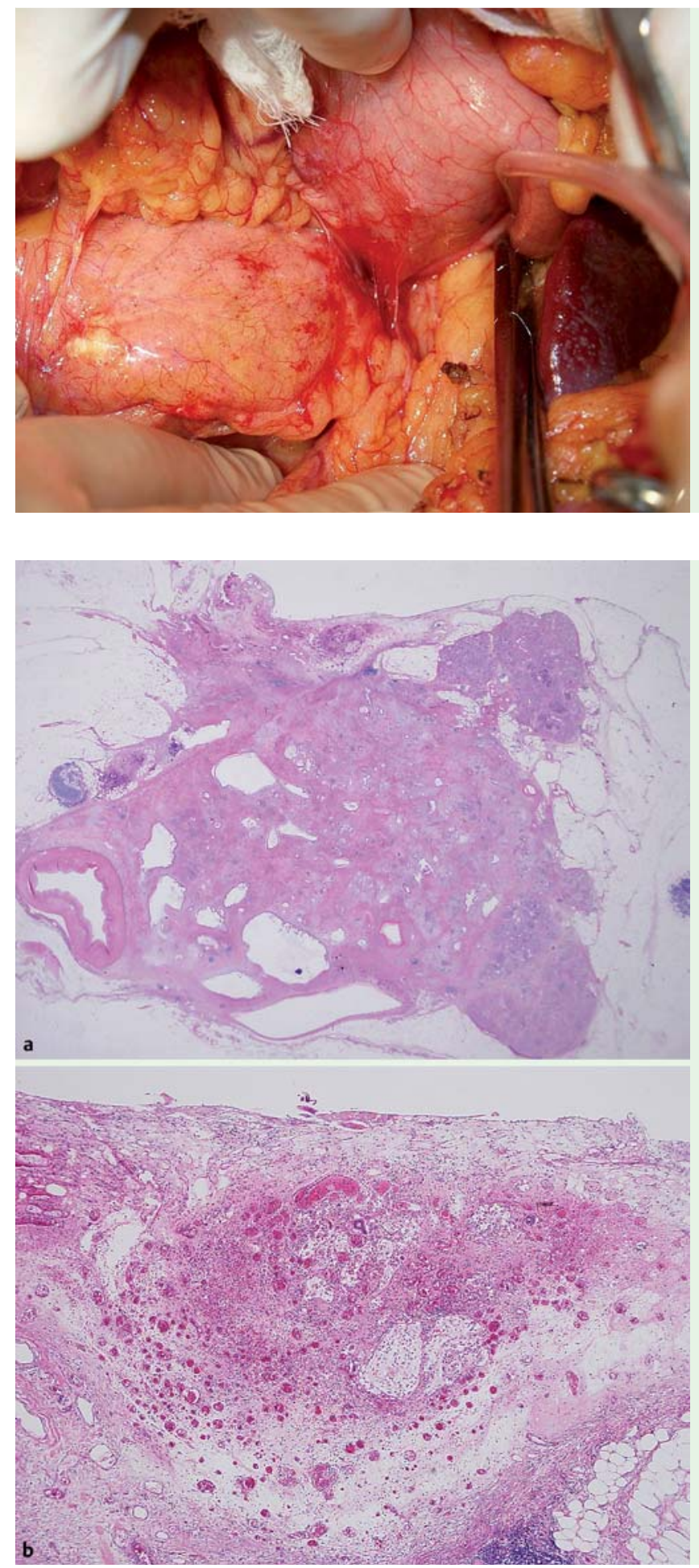

Fig. 1 Intraoperative findings. Bleeding and adhesion were observed at the puncture sites. Tumor resection was possible.

Fig. 2 a, b Histopathological findings from the resected specimen. Bleeding was observed at a site distal from the primary tumor, with tumor cells seen within lymphatic vessels in the sites of bleeding.
The use of endoscopic ultrasound-guided fine-needle aspiration (EUS-FNA) has been rapidly expanding as a useful examination technique which enables highly accurate histological diagnosis. Reports of tumor dissemination induced by EUS-FNA are rare [1 -5]. We recently encountered a case in which tumor cells were observed in the puncture line in a surgically resected specimen after EUS-FNA, and in which dissemination in the posterior wall of the upper gastric body was later observed.

The patient was a 68-year-old woman. A computed tomography (CT) scan revealed a 2-cm mass in the pancreatic body, which was suspected to be pancreatic cancer. We scheduled distal pancreatectomy, and to obtain a definitive diagnosis the patient underwent preoperative EUS-FNA with a 22-gauge needle (Olympus Medical Systems, Tokyo, Japan) inserted four times, which yielded a diagnosis of adenocarcinoma. No clinical complications developed after EUS-FNA. Distal pancreatectomy was performed 20 days after the EUS-FNA and, intraoperatively, bleeding and adhesion were observed at the puncture sites ( $\bullet$ Fig. 1). Histopathology of the surgically resected specimen confirmed adenocarcinoma (T2NOM0). A small number of tumor cells were found within the lymphatic vessels of the resected specimen, similar to the areas of bleeding and adhesion ( $\bullet$ Fig. 2).

At 22 months after distal pancreatectomy, upper gastrointestinal endoscopy revealed a submucosal tumor-like mass in the posterior wall of the upper gastric body ( Fig. 3a), which was subsequently confirmed to be adenocarcinoma by biopsy ( $\bullet$ Fig.3b). An abdominal CT scan did not reveal any local recurrence at the resected site of the pancreas or lymph node metastasis around the stomach, but a tumor was observed on the posterior wall of the gastric body ( $\bullet$ Fig.4).

In the present case, bleeding was seen at the puncture sites and tumor cells were observed within the lymphatic vessels in these areas. As similar findings were absent in the areas which were free of bleeding or adhesion, we speculated that the punctures caused the bleeding and adhesion, and that subsequent reactive changes facilitated the survival of tumor cells within the lymphatic vessels. Moreover, it is possible that similar changes occurred in the gastric wall.

Endoscopy_UCTN_Code_CPL_1AL_2AD 


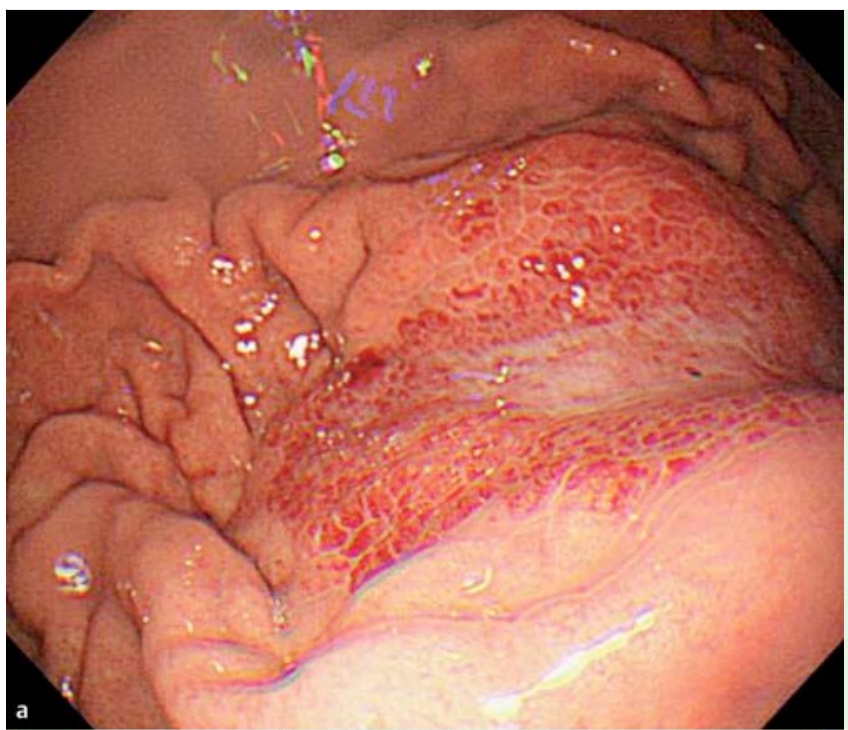

Fig. 3 a A tumor can be observed on the posterior wall of the upper gastric body. b Adenocarcinoma, as confirmed by biopsy.
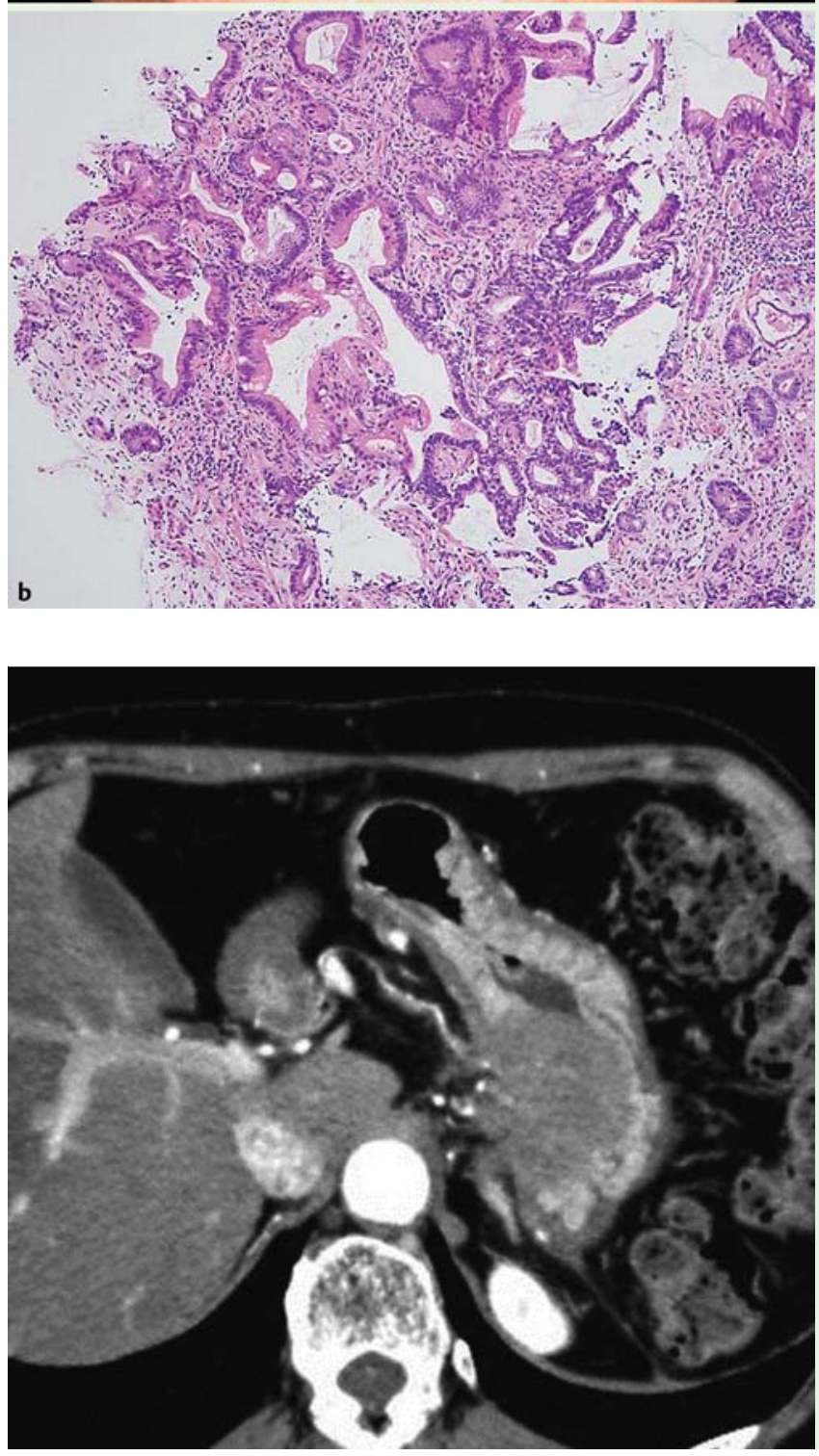

Fig.4 Abdominal computed tomography scan revealed a tumorous lesion on the gastric wall, but did not show any signs of local recurrence.

Competing interests: Dr. Takao Itoi gives lectures for and is a consultant for Olympus Medical Systems. All other authors declare that they have no financialrelationships or other conflicts of interest relevant to this publication.

\section{A. Katanuma ${ }^{1}$, H. Maguchi ${ }^{1}$,}

S. Hashigo ${ }^{1}$, M. Kaneko ${ }^{1}$, T. Kin ${ }^{1}$,

K. Yane ${ }^{1}$, R. Kato ${ }^{1}$, S. Kato ${ }^{1}$, R. Harada ${ }^{1}$, M. Osanai ${ }^{1}$, K. Takahashi ${ }^{1}$, T. Shinohara $^{2}$, T. Itoi $^{3}$

${ }^{1}$ Center for Gastroenterology,

Teine-Keijinkai Hospital, Sapporo, Japan

2 Department of Pathology,

Teine-Keijinkai Hospital, Sapporo, Japan

3 Department of Gastroenterology, Tokyo

Medical University, Tokyo, Japan

\section{Acknowledgment}

$\nabla$

We thank Professor J. Patrick Barron of the International Medical Communications Center of Tokyo Medical University for his revision of this article.

\section{References}

1 Shah JN, Fraker D, Guerry D et al. Melanoma seeding of an EUS-guided fine needle track. Gastrointest Endosc 2004; 59: 923-924

2 Paquin SC, Gariepy G, Lepanto L et al. A first report of tumor seeding because of EUSguided FNA of a pancreatic adenocarcinoma. Gastrointest Endosc 2005; 61: 610-611

3 Doi S, Yasuda I, Iwashita T et al. Needle tract implantation on the esophageal wall after EUS-guided FNA of metastatic mediastinal lymphadenopathy. Gastrointest Endosc 2008; 67: 988-990

4 Hirooka $Y$, Goto $H$, Itoh $A$ et al. Case of intraductal papillary mucinous tumor in which endosonography-guided fine-needle aspiration biopsy caused dissemination [letter]. J Gastroenterol Hepatol 2003; 18: $1323-1324$

5 Chong A, Venugopal K, Segarajasingam D et al. Tumor seeding after EUS-guided FNA of pancreatic tail neoplasia. Gastrointestinal Endosc 2011; 74: 933 -956

Bibliography

Dol http://dx.doi.org/

10.1055/s-0031-1291716

Endoscopy 2012; 44: E160-E161

(c) Georg Thieme Verlag KG

Stuttgart · New York

ISSN 0013-726X

Corresponding author

\section{A. Katanuma, MD}

Center for Gastroenterology

Teine-Keijinkai Hospital

1-40 Maeda 1-jo 12-chome

Teine-ku

Sapporo 006-8555

Japan

Fax: +81-11-6852967

akio-ka@ta2.so-net.ne.jp 